\title{
A incorporação da temática de gênero e diversidade na academia: por uma ecologia de saberes na universidade
}

\section{The incorporation of themes of gender and diversity in the academy: for an ecology of knowledge in the university}

\author{
Márcia Alves da Silva*
}

\begin{abstract}
RESUMO
Neste texto procuramos resgatar aspectos da trajetória do Observatório de Gênero e Diversidade da Universidade Federal de Pelotas - UFPel desde sua fundação, em 2014, até o final de 2016. Salientamos as principais ações para uma reflexão sobre a caminhada executada até o momento, identificando e problematizando seus avanços e seus limites. Nesta escrita, inicialmente se problematiza a difícil relação entre ciência feminista e educação escolar. $\mathrm{Na}$ sequência, é realizada uma crítica da racionalidade hegemônica, tendo por base a obra de Boaventura Santos, apontando para o que o autor chamou de ecologia de saberes, incorporando a experiência do Observatório nessa perspectiva. Por fim, são apresentadas algumas iniciativas realizadas pelo Observatório no período mencionado, considerando a indissociabilidade do ensino, da pesquisa e da extensão acadêmica.
\end{abstract}

Palavras-chave: Teoria feminista. Universidade. Gênero e diversidade.

\begin{abstract}
This text seeks to recover aspects of the trajectory of the Observatório de Gênero e Diversidade ("Gender and Diversity Observatory") of the Federal University of Pelotas (UFPel), from its foundation in 2014 until the end of 2016. It highlights its main actions, seeking to raise a reflection on the walk carried out so far, identifying and problematizing its advances and

* Universidade Federal de Pelotas. Faculdade de Educação. Pelotas, Rio Grande do Sul, Brasil. E-mail: profa.marciaalves@gmail.com. https://orcid.org/0000-0002-4727-2623.
\end{abstract}


its limits. In this writing, initially, I will problematize the difficult relation between feminist science and school education. In a second moment, a critique of hegemonic rationality is made, based on the work of Boaventura Santos, pointing to what the author has called ecology of knowledge, and incorporating the experience of the Observatório in this perspective. Finally, I will present some initiatives carried out by the Observatory during the mentioned period, considering the inseparability of teaching, research and academic extension.

Keywords: Feminist theory. University. Gender and diversity.

\section{Introdução}

Neste trabalho propomos o resgate da trajetória do Observatório de Gênero e Diversidade da Universidade Federal de Pelotas - UFPel, salientando suas ações para uma reflexão sobre a caminhada executada até o momento, identificando e problematizando seus avanços e seus limites. Esmeraldo (2010) afirma que conhecer a trajetória de redes de grupos de estudo sobre gênero e diversidade nas instituições de ensino, também de pesquisadoras feministas, além de ter valor histórico e científico, possibilita a consolidação e expansão da rede, consequentemente, ampliando a visão da relevância social dos estudos de gênero.

Deste modo, programas, como o do Observatório de Gênero e Diversidade, possuem papel essencial numa instituição de proporções como a Universidade Federal de Pelotas, papel esse de caráter formador e transformador, que evidencia o contributo de suas diversas ações e projetos no desenvolvimento das funções acadêmicas. Dito de outra forma, podemos salientar a importância de incorporar as temáticas de gênero e diversidade nos currículos dos cursos oferecidos pela instituição, de incentivar o desenvolvimento de projetos de extensão que envolvam a comunidade exterior à instituição e o de projetos de pesquisa nas temáticas trabalhadas pelo grupo, tudo para cumprir, assim, com a tripé pesquisa-ensino-extensão, de forma interdisciplinar e transversal.

A proposta da criação de um Observatório de Gênero e Diversidade na UFPel surgiu em janeiro de 2014, como uma iniciativa da Pró-Reitoria de Extensão e Cultura da UFPel (PREC), com o intuito de formar um espaço institucional interdisciplinar que possibilitasse, em primeiro lugar, a aproximação de pesquisadores/as da própria instituição e de diversas áreas do conhecimento que atuam no tema. Esses estudiosos, no cotidiano da instituição, estavam dispersos em suas unidades acadêmicas e áreas de conhecimento e atuação. O pontapé inicial nesse sentido foi dado por grupos externos à instituição que, constituídos 
na cidade, atuam nas temáticas gênero e diversidade (como o Conselho Municipal dos Direitos da Mulher e o Grupo Autônomo de Mulheres de Pelotas). Essas entidades solicitaram à PREC que viabilizasse a criação de um espaço na e da Universidade que agregasse a atuação neste âmbito. Dessa forma, desde 2014, o objetivo do Observatório tem sido o de fortalecer as atuações da UFPel neste âmbito, a fim de ampliar e qualificar a rede de atuação nas áreas de gênero e diversidade em Pelotas e na região, incentivando ações em parceria com outras instituições, tanto governamentais como não governamentais. De modo que fica evidente o caráter extensionista da proposta que, embora valorize a pesquisa e $o$ ensino, buscava intervir diretamente em ações com a comunidade local e regional. O fato do grupo ter sido criado pela PREC da instituição denota esse aspecto.

Nesta escrita, inicialmente se problematiza a difícil relação entre ciência feminista e sistema de ensino, pois sabemos o quanto a teoria feminista historicamente tem sido invisibilizada nos currículos escolares, em todos os níveis de ensino, inclusive no ensino superior. Na sequência, apresenta-se uma crítica da racionalidade hegemônica, a partir da crítica da razão indolente de Boaventura Santos (2000), apontando para a construção do que ele chamou de ecologia de saberes (SANTOS, 2007), incorporando a experiência do Observatório nessa perspectiva. Por fim, são apresentadas algumas ações do Observatório, realizadas no período de 2014 a 2016, levando em consideração a indissociabilidade do ensino, da pesquisa e da extensão acadêmica, elementos chave na proposta do grupo.

\section{A invisibilidade da teoria feminista nos espaços educacionais}

Reconhecemos que foi a partir dos movimentos feministas, conforme Blay (2006), que se evidenciou, na ciência acadêmica, a ausência do conhecimento sobre as mulheres, suas contribuições culturais e demandas específicas. Entendemos, como Schiebinger (2001, p. 37), que “[...] a ciência moderna é um produto de centenas de anos de exclusão das mulheres; o processo de trazer mulheres para a ciência exigiu, e vai continuar a exigir profundas mudanças estruturais na cultura, métodos e conteúdo da ciência".

Chassot (2006), tentando responder a indagação por que a ciência foi ou é masculina, identifica o que chamou de nossa tríplice ancestralidade, isto é, que temos ancestralidade grega, judaica e cristã. O que privilegia o poder religioso na construção da exclusão das mulheres no processo de construção do conhecimento científico, de uma religião masculina, como afirma o autor. Segundo ele: 
Para cada uma dessas três raízes, se trazem tentativas de leituras: na grega, os mitos e as concepções biológicas de fecundação de Aristóteles; na judaica, a cosmogonia, particularmente a criação de Adão e Eva; e, na cristã, aditada às explicações emanadas do judaísmo, a radicalidade de interpretações como aquelas trazidas por teólogos eminentes como Santo Agostinho, Santo Isidoro e Santo Tomás de Aquino, entre outros. (CHASSOT, 2006, p. 46).

Assim como as mulheres foram, historicamente, excluídas da produção de conhecimento científico, da mesma forma as temáticas de gênero e sexualidade também foram pouco incorporadas nos currículos acadêmicos, apesar da considerável produção advinda da teoria feminista e dos estudos de gênero.

Essa situação é consequência direta de muito tempo de exclusão das mulheres na história da humanidade. Colling (2014) vai identificar e desenvolver os diversos discursos que foram se somando e se complementando na construção do feminino. Basicamente ela identificou discursos filosóficos, médicos e religiosos, entre outros, que acabam sendo incorporados a discursos pedagógicos hegemônicos que vão constituir uma determinada representação de mulher, tanto nas teorias como nas práticas cotidianas. São essas construções que consolidam uma concepção de feminino como ser subalterno e inferior e que, ao longo do tempo, vão se materializando em representações naturalizadas sobre as mulheres e outras identidades sexuais não masculinas.

Essas representações do feminino e da sexualidade vão, ao longo do tempo histórico correspondente, se conformando no que podemos denominar preconceito de gênero. Agnes Heller (2008) abordou o tema preconceito em sua relação com a cotidianidade, reconhecendo a historicidade dessa construção. Para ela, o preconceito é uma categoria do pensamento cotidiano que se materializa em comportamentos sociais. O pensamento cotidiano é um pensamento baseado na experiência, portanto, empírico e - o que a autora denomina - ultrageneralizador.

A ultrageneralização característica do nosso pensamento e comportamento cotidianos são obtidos por meio de dois aspectos básicos e complementares: por um lado, assumem estereótipos e esquemas já elaborados; por outro lado, estes são transmitidos pelo meio social em que vivemos. Para Heller, esse processo de ultrageneralização é inevitável na vida cotidiana e sempre constitui um juizo provisório. Embora reconheça que nem todo juízo provisório possa ser considerado preconceito, "o preconceito é um tipo particular de juízo provisório" (HELLER, 2008, p. 65).

Portanto, podemos nos aproximar de uma definição de preconceito que Heller denominou juízo provisório falso. Para ela, “os juízos provisórios refu- 
tados pela ciência e por uma experiência cuidadosamente analisada, mas que se conservam inabalados contra todos os argumentos da razão, são preconceitos" (HELLER, 2008, p. 68).

Assim temos motivo para acreditar que toda a construção científica da abordagem de gênero e sexualidade tenha sofrido o preconceito histórico de se constituir em falsos juízos provisórios, no que Heller (2008) denominou de preconceitos de grupo, como algo que afetou não apenas algumas pessoas individualmente, mas um grupo considerável de pessoas ao longo da história da humanidade.

Nossos motivos de suspeita se baseiam, portanto, num processo muito forte de invisibilidade social e preconceito, ao qual as mulheres historicamente têm sido vítimas, sendo essa situação causada por vários fatores, tanto de caráter econômico como político e social.

Assim como afirmamos anteriormente, Colling (2014) identificou diversos discursos construídos sobre o feminino em vários âmbitos. No entanto, outras construções, de ordem econômica e social, também colaboraram na construção de uma inferioridade feminina. Podemos citar a obra de Federici (2017), em que desenvolveu um denso estudo sobre a origem do capitalismo e a participação das mulheres nesse processo. Nessa obra, a pesquisadora lança um novo olhar sobre o processo, situando seu foco de análise no período histórico da Idade Média, especificamente no período de caça às bruxas na Europa. Para ela, o processo de caça às bruxas teve como objetivo transformar o papel e o perfil das mulheres na sociedade, adaptando-as às necessidades do capitalismo comercial e mercantil nascente, pois, para que o capitalismo triunfasse perante o feudalismo, era necessário que fosse suplantada as relações sociais e de produção feudais, para isso seriam necessárias transformações profundas no que se refere às mulheres. Na nova sociedade, seria necessário a divisão entre trabalho produtivo e reprodutivo, cabendo às mulheres a responsabilidade pelo trabalho reprodutivo. Em vista desse objetivo, foi implementado uma série de ações que teriam como meta delimitar as atividades das mulheres quase que exclusivamente aos espaços domésticos, para que cumprissem com esse propósito. Dito de outra forma, a separação entre espaços públicos e privados nunca na história da humanidade foi feita de forma tão profunda, haja vista a necessidade de acumulação de capital.

Segundo Federici (2017), a caça às bruxas buscou destruir com todo uma certa autonomia que as mulheres possuíam, incluindo o controle sobre o próprio corpo, o conhecimento de elementos advindos da natureza, como plantas, flores etc. (pois muitas mulheres acusadas de "bruxaria" eram na verdade curandeiras, parteiras, entre outras). Enfim se tratavam de mulheres que detinham certas parcelas de saberes e conhecimentos que, na nova sociedade que despontava, passavam a ser desnecessários e incômodo manter. Com isso, é possível perceber 
o quanto foi violento o processo de estruturação do sistema capitalista, no qual as mulheres tiveram especial atenção, pois se sabia o quanto era necessária sua mão de obra para a consolidação e manutenção do sistema.

À vista disso, no modelo capitalista de sociedade, desenvolvem-se aspectos constitutivos de um modelo de sociedade que discrimina as mulheres em diversos âmbitos, numa naturalização de inferioridade que se alicerça em discursos de cunho religioso, biológico, econômico e social.

Assim é possível percebermos o quanto é difícil a caminhada de construção de uma teoria feminista, enquanto uma construção científica que pouco tem sido reconhecida no mundo acadêmico. Os espaços escolares, portanto, reproduzem essa invisibilidade, já posta no mundo científico e também na vida social.

No Brasil, o encontro entre a educação escolar e a perspectiva de gênero e sexualidade sempre foi problemático. Foucault já descrevia as escolas da Europa do século XVIII como verdadeiras maquinarias que permaneciam em constante estado de alerta. Segundo o autor, "O espaço da sala, a forma das mesas, o arranjo dos pátios de recreio, a distribuição dos dormitórios [...], os regulamentos elaborados para a vigilância do recolhimento e do sono, tudo falava da maneira mais prolixa da sexualidade" (FOUCAULT, 1984, p. 30).

A partir dos anos 1960, os movimentos sociais pelos direitos civis, as lutas feministas, os movimentos LGBTTs (gays, lésbicas, bissexuais, transgêneros e travestis), as reivindicações étnico-raciais produziram marcas no discurso sobre as instituições de ensino. Entretanto, nesse mesmo período, o interesse crescente pela educação sexual entre os educadores levou à apresentação de um projeto de lei propondo a introdução da educação sexual nas escolas primárias e secundárias do país (WEREBE, 1998, p. 173). Fora justamente nesse momento que todo esse movimento foi reprimido pela ditadura militar. Temos então a proibição da exposição de temas ligados à sexualidade nas escolas brasileiras. Como a ditadura impôs um regime de controle e moralização dos costumes, a educação sexual foi definitivamente banida de qualquer discurso escolar por parte do Estado.

As discussões sobre gênero, educação sexual ou feminismo surgem como parte de um projeto de escola com base nas lutas pela redemocratização e, nesse exato momento, a educação sexual aparece como uma reivindicação importante do movimento feminista brasileiro, pois, segundo Brusquini e Barroso (1983), projetos de educação sexual estiveram fortemente ligados a intelectuais feministas. Observa-se, então, o movimento de luta contra o patriarcado encaminhado por feministas como base para tantas outras lutas e como uma proposta libertadora não apenas das mulheres, mas também da população LGBTTs.

A partir do movimento iniciado por feministas, podemos então adentrar nas questões de gênero. Ao abordarmos gênero como categoria de investiga- 
ção, precisamos recusar os lugares definidos pela dicotomia entre masculino e feminino, além de reconstruir os significados dos corpos, dos desejos e dos prazeres (SCOTT, 1995). É necessário recordarmos que todos os projetos de educação sexual dos anos de luta partiram de uma perspectiva de liberdade que foram representadas pelas abordagens feministas.

\section{Por uma ecologia de saberes de gênero e diversidade}

Boaventura Santos desenvolve uma crítica que denomina razão indolente (2000), consistindo essa na racionalidade hegemônica, baseada em categorias reducionistas que, por isso, mantêm na invisibilidade uma diversidade de conhecimentos e de possibilidades de ver e atuar no mundo. Uma das formas na qual a razão indolente se manifesta é o que o autor chama de metonímica, que traz, em seu âmago, uma noção de totalidade, mas de forma sempre reducionista, "porque contrai o presente ao deixar de fora muita realidade que não é considerada relevante e que se desperdiça” (SANTOS, 2007, p. 27). Baseia-se em duas ideias principais: a dicotomia e a hierarquia. Nessa perspectiva, o mundo e o conhecimento sobre esse mundo são vistos de forma dicotômica, por exemplo, homem-mulher, norte-sul, cultura-natureza etc. São dicotomias que, além de reduzirem o todo social, hierarquizam, pois escondem diferenças e pluralidades.

Nessa perspectiva, percebemos a ausência da ciência feminista e dos estudos de gênero nos currículos acadêmicos da instituição em questão. $\mathrm{Na}$ UFPel identificamos apenas um curso de graduação que possui no currículo uma disciplina obrigatória. Em alguns outros poucos cursos, o que se percebe são algumas disciplinas ofertadas de forma optativa. Para combater a razão metonímica, Santos (2007, p. 28-29) propõe desenvolver o que ele denomina sociologia das ausências, como sendo "[...] um procedimento transgressivo, uma sociologia insurgente para tentar mostrar que o que não existe é produzido ativamente como não existente, como uma alternativa não crível, como uma alternativa descartável, invisível à realidade hegemônica do mundo". Dessa forma, a sociologia das ausências procura romper com esse ciclo de invisibilidades, trazendo à tona e tornando visíveis os diversos contextos obscurecidos pela lógica hegemônica da ciência.

Santos (2007) identifica, ainda, cinco formas de produção das ausências que funcionam em prol do que ele denomina monocultura, que nada mais é do que a construção da razão indolente. A primeira delas diz respeito ao que ele denomina monocultura do saber e do rigor e que se refere ao reconhecimento 
do saber científico como sendo único em importância e rigor. Essa perspectiva é reducionista, pois exclui diversos conhecimentos e práticas, em grande medida advindos de movimentos sociais e culturas populares. Na contracorrente dessa monocultura constituidora da razão indolente, o Observatório assumiu o desafio de estabelecer um diálogo entre os saberes acadêmicos e os conhecimentos populares, especialmente no que se refere ao seu caráter extensionista, sempre voltado a incorporar a sociedade civil e os movimentos sociais organizados na área de gênero e diversidade.

A segunda monocultura é a do tempo linear, que se materializa na ideia de que a existência tem um sentido único, uma direção, e que os países ditos desenvolvidos estão numa escala superior, trazendo à tona a ideia evolucionista de progresso, modernização etc. A terceira monocultura se refere ao processo de naturalização das diferenças, que invisibilizam hierarquias, utilizando como argumento a natureza. Nas questões de gênero, articuladas com questões étnicas e de classe, essa forma de produção de ausências é muito comum. O espaço acadêmico historicamente se constituiu como um lócus dessas ausências, invisibilizando as temáticas de gênero e diversidade nas instituições, tanto no que se refere ao conteúdo científico, por sua ausências nas estruturas curriculares dos cursos, como temática a ser debatida nos mais diversos espaços das instituições. Essa era a realidade vivida pela universidade antes da criação desse espaço. É necessário reconhecer que, antes da criação do Observatório, já havia alguns pesquisadores/as e grupos de pesquisas operando nessas temáticas na instituição, mas, até então, suas ações eram mais dispersas, atuando de forma isolada em suas respectivas faculdades e/ou institutos.

A quarta monocultura da produção de ausência diz respeito à escala dominante que, na relação entre o global e o local, privilegia o primeiro, de forma que a globalização e o universalismo tornam-se com grande status, invisibilizando e desprezando tudo que é local. Logo, as mais diversas culturas e saberes locais são excluídos. Por fim, a última monocultura citada por Santos diz respeito à monocultura do produtivismo capitalista. É a ideia de que o crescimento econômico é a prioridade e, dessa maneira, justifica toda a forma de exploração do trabalho humano. Assim todas as culturas e saberes locais e populares passam a ser subservientes à lógica do mercado.

À vista disso, a estratégia a ser adotada pela sociologia das ausências, segundo Santos (2007), deve ser a substituição das cinco monoculturas pelo que ele chama de cinco ecologias, que são: ecologia dos saberes, ecologia das temporalidades, ecologia do reconhecimento, ecologia da transescala e ecologia das produtividades. Aqui nos detemos na ecologia dos saberes, enquanto fundamental na construção do Observatório. 
A ecologia dos saberes propõe construir uma contra hegemonia da ciência tradicional e hegemônica, superando a ideia de monocultura de saberes, mas sendo apenas um saber, enquanto parte de uma ecologia ampla de saberes, na qual o saber científico seja apenas um entre tantos outros saberes, como o saber popular, o saber de populações urbanas marginais, o saber camponês, indígena etc. Dessa maneira, o Observatório teve, desde sua origem, a premissa de assumir o desafio de compartilhar o conhecimento e fomentar o debate extensionista, de forma a se inserir no contexto local e criar alternativas e formas de atuação com grupos locais organizados, na perspectiva dialética enquanto possibilidade de construção de novos conhecimentos, para não apenas contemplar a realidade, mas intervir nela.

\section{A indissociabilidade do ensino, da pesquisa e da extensão em gênero e diversidade: algumas ações implementadas pelo Observatório}

Uma dimensão fundamental a ser considerada é a interdisciplinaridade que o Observatório de Gênero e Diversidade promove em função de seus componentes. Ele articula diversas áreas do conhecimento oriundas não só da UFPel, mas também de outras instituições e grupos organizados na cidade e na região, buscando atuar na perspectiva da indissociabilidade do ensino, da pesquisa e da extensão.

Sobre essa indissociabilidade, Boaventura Santos identifica uma crise das teorias na contemporaneidade. Sobre isso denuncia que

Hoje vivemos um problema complicado, uma discrepância entre teoria e prática social que é nociva para a teoria e também para a prática. Para uma teoria cega, a prática social é invisível; para uma prática cega, a teoria social é irrelevante. E essa é uma situação que temos de atravessar se tentamos entrar no âmbito da articulação entre os movimentos sociais. (SANTOS, 2007, p. 20).

Em relação ao ensino, o Observatório busca estimular a atuação de seus/ suas docentes em disciplinas que tratem do tema. Há, no corpo de docentes vinculados ao Observatório, em torno de 30 docentes que atuam em disciplinas - tanto na graduação como na pós-graduação - que abordam o tema, mas se 
trata ainda de ações um tanto isoladas e dispersas se pensarmos na dimensão de uma Universidade como a UFPel, que possui hoje quase 100 cursos de graduação e cerca de 20 mil alunos/as. É uma importante missão do Observatório ampliar o número de professores/as que trabalham com gênero e diversidade, assim como a quantidade de disciplinas que abordam o tema, contribuindo, por consequência, para a formação desses/as alunos/as e aprimorando o ensino na graduação e pós-graduação.

Uma das iniciativas tomadas foi a criação da disciplina denominada $E s$ tudos de Gênero e Diversidade, que tem sido ofertada para todos os cursos de graduação da instituição em forma de cadeira optativa, portanto, não obrigatória. Essa disciplina é ofertada por módulos, sendo a carga horária composta de 64 horas/aula, e é ofertada de forma compartilhada por docentes vinculados/ as ao Observatório. Alguns módulos já trabalhados foram: estudos de gênero e teoria feminista, diversidade e educação; gênero, diversidade, raça e etnia; gênero, diversidade e arte; gênero, diversidade e trabalho; teorias sobre gênero e diversidade; entre outras. Tem-se o cuidado que os docentes assumam módulos que estejam de acordo com suas áreas de atuação. Cabe salientar que todos os docentes são doutores e pesquisadores nas temáticas de gênero e diversidade, nas suas intersecções com suas áreas de formação. Como já dito anteriormente, $o$ grupo é formado por professores de várias unidades e cursos da UFPel, portanto com formações diversas, como antropologia, sociologia, educação física, artes, letras, arquitetura, direito, psicologia, história e enfermagem.

A disciplina surpreendeu o grupo pela grande procura, o que demonstra a necessidade de abordarmos o tema já na formação dos/as acadêmicos/as na graduação. A intenção inicial era ofertar apenas uma turma inicialmente. Já na primeira semana haviam 300 estudantes interessados/as em cursar. Assim foram oferecidas duas turmas de forma concomitante.

No que diz respeito à pesquisa acadêmica, o Observatório possui, entre seus membros, pesquisadores/as que atuam e coordenam investigações nessa temática, além de atuarem em disciplinas que abordam o tema e desenvolvem em suas unidades atividades de extensão com a comunidade. Esse fato auxilia num processo de articulação entre pesquisa, ensino e extensão, já que alguns/ mas envolvidos/as já atuam nessa perspectiva. Entre as metas do Observatório estão: aproximar e fazer dialogar as experiências investigativas referentes a gênero e diversidade já existentes na UFPel, além de estimular o desenvolvimento de novos estudos sobre o tema. Dessa aproximação já existem novas pesquisas interdisciplinares que estão sendo implementadas.

No que se refere à extensão, o Observatório já nasce com parcerias externas consolidadas, sendo sua participação no Conselho Municipal dos Direitos da Mulher do município um exemplo disso. Com a participação do Observatório 
nesse espaço, a comunidade da UFPel pode acessar - via encaminhamento outras instituições, como a rede de proteção às mulheres vítimas de violência da cidade, formada pela Delegacia de Atendimento à Mulher (DEAM) e pelo Centro de Referência no Atendimento às Mulheres Vítimas de Violência de Pelotas (órgão da Prefeitura de Pelotas que presta atendimento psicológico para mulheres vítimas de violência).

Importante ressaltar que, desde 2014, o Observatório possui um assento no Conselho Municipal dos Direitos da Mulher na cidade de Pelotas/RS. Esse fato coloca a instituição em um espaço importante de estabelecimento e implementação de políticas públicas para o município. Entre 2014 e 2015, o Observatório encabeçou uma campanha contra a violência de gênero com jovens acadêmicas, a partir de uma série de denúncias de casos de violência com discentes da Universidade. A campanha foi denominada Pelotas Sem Medo, quando mais de vinte entidades locais construíram um documento que, divulgado na mídia, abriu um espaço para a discussão do tema em diversos setores da sociedade, como programas de debates em rádio e televisão, panfletagens em espaços públicos etc. Além disso, a campanha foi fortemente divulgada na própria instituição, a partir da criação e divulgação de uma identidade visual que facilitou a divulgação desse movimento. A Coordenadoria de Comunicação Social (CCS) e a Rádio Federal FM se somaram à iniciativa e em muito auxiliaram na divulgação da campanha.

Outra iniciativa extensionista que vale a pena salientar ocorreu em 2015, quando o Observatório organizou uma Pré-Conferência dos Direitos das Mulheres na UFPel, voltada especialmente para a comunidade universitária. O evento foi uma atividade preparatória para a Conferência Municipal dos Direitos da Mulher que, por sua vez, encaminharia os resultados para a Conferência Nacional. Esses momentos foram importantes, pois se trata de espaços para a construção de pautas feministas a serem executadas tanto a nível local, como estadual e nacional, sendo um espaço importante na construção de políticas públicas para as mulheres. Várias pré-conferências foram realizadas na cidade e, pela primeira vez, foi realizada uma na própria instituição, voltada para as suas próprias demandas internas, incorporando-as numa pauta mais geral a ser somadas com as demais.

No que se refere à divulgação científica, entre os dias 18 e 20 de maio de 2016, o Observatório realizou o I Simpósio de Gênero e Diversidade: debatendo identidades, a fim de ampliar o debate entre pesquisadores, estudantes e comunidade em geral sobre a produção acadêmica nas áreas de gênero e diversidade. $\mathrm{O}$ evento se organizou a partir de oito eixos temáticos, que foram: mulheres do campo, saúde, educação, trabalho, artes, sexualidades, violência e, ainda, raça e etnia. Além de ampliar e dar visibilidade a esses temas na própria instituição, o evento logrou expandir suas conexões de modo a envolver outros grupos, 
centros e núcleos de gênero no estado e no país, já que trouxe à cidade diversos palestrantes de outras instituições do país.

Pensamos que esse momento foi de grande importância para o grupo, pois além de servir aos mesmos propósitos de qualquer evento acadêmico, como divulgar a produção científica sobre o tema, propiciar um espaço de intercâmbio entre pesquisadores e estudantes, também de certa forma pode nos consolidar perante a instituição e a comunidade como um novo espaço de produção de conhecimento.

\section{Considerações finais}

Consideramos importante ressaltar alguns limites e dificuldades apresentadas até o momento. Uma delas se refere à estrutura físico-financeira do grupo, ainda frágil. A estrutura física se constitui de uma pequena sala, com alguns móveis e equipamentos de informática. Não há servidor do quadro permanente da instituição, mas discentes bolsistas e voluntários que atuam nesse espaço.

Outro elemento que podemos destacar é a ausência de parcela de investigadoras/es dessas temáticas da própria instituição. Por motivos diversos e pouco explicitados, houve docentes que atuam na área que não contribuíram com a construção do grupo e, portanto, não participaram do Observatório. Sobre isso poderíamos levantar várias hipóteses, mas sempre correndo o risco de cometer erros e imprecisões. Algumas hipóteses levantadas pelo próprio grupo foram: intensificação do trabalho docente (que pode envolver uma alta carga horária em suas unidades de origem que impediu seu envolvimento nessa proposta); falta de interesse pessoal na proposta por motivos de ordem diversa e, ainda, divergências políticas em relação ao grupo que atuava na gestão da própria Universidade (a criação do Observatório se deu como ação de uma gestão específica na Universidade, onde membros vinculados a outros grupos de sustentação e apoio a outras candidaturas oponentes à gestão da UFPel vincularam o Observatório a essa determinada gestão).

Em tempos de grande individualismo, inclusive acadêmico, o Observatório representa uma experiência que, de certa forma, se coloca na contramão do contexto atual. O Observatório nasceu em uma Pró-Reitoria de Extensão, e sabemos que, nas instituições acadêmicas, a extensão não é praticada por todos/ as os/as pesquisadores/as e é, inclusive, muitas vezes desvalorizada.

Outro elemento importante a ser considerado é a necessidade da instituição ampliar o número de disciplinas a serem ofertadas, incluindo formalmente esses temas no currículo dos cursos acadêmicos. Para isso, alguns desafios precisam 
ser enfrentados, como a necessidade de aumentar a contratação de docentes que atuam nessas áreas na instituição e fomentar mudanças curriculares nos cursos da instituição. São questões que balizam profundas mudanças que passam por concepções de formação acadêmica, de currículo, de conhecimento e de ciência etc.

Enfim, encerramos este texto com a certeza de que vivemos tempos políticos muito difíceis. Essa escrita se refere basicamente ao processo de criação do Observatório e a sua atuação, de 2014 até 2016. Mas sabemos que hoje o país enfrenta um outro momento. O projeto da Escola sem Partido toma fôlego no país e se configura como uma grande ameaça ao desenvolvimento desses temas nos espaços de ensino e na sociedade de forma geral. Essa proposta conservadora despolitiza a educação, pois, de acordo com Frigotto (2016, não p.), quer defender "o partido absoluto e único: partido da intolerância com as diferentes ou antagônicas visões de mundo e conhecimento, de educação, de justiça, de liberdade; partido, portanto da xenofobia nas suas diferentes facetas: de gênero, de etnia, da pobreza e dos pobres, etc."

É importante destacar o caráter de religiosidade que alicerça esse pensamento, sustentado, em grande parte, por instituições religiosas de caráter fundamentalista. Desse modo, vemos materializado o que Heller (2008) chama de fixação afetiva do preconceito, que nada mais é do que a fé. Assim podemos inferir que é a fé que sustenta o alicerce de manutenção do preconceito de gênero que, na atualidade, tem se configurado no projeto da Escola sem Partido.

Não é à toa que esse projeto político-pedagógico possui caráter conservador, pois Heller já admitia que os preconceitos, na sua grande maioria, são produtos das classes dominantes, pois essas "desejam manter a coesão de uma estrutura social que lhes beneficia” (HELLER, 2008, p. 77). Logo, o patriarcalismo ${ }^{1}$ busca sua manutenção nessas iniciativas.

Portanto o processo de luta acadêmica e política de construção do Observatório de Gênero e Diversidade da UFPel se coloca na perspectiva de defesa da construção do que Santos (2007) vai denominar sociologia das emergências. Enquanto a sociologia das ausências denuncia o caráter de invisibilidade de experiências contra-hegemônicas, a sociologia das emergências dá visibilidade e fomenta a construção de experiências contra hegemônicas possíveis. Conforme Santos (2007, p. 38), "a sociologia das emergências é a que nos permite abandonar essa ideia de um futuro sem limites e substituí-la pela de um futuro concreto, baseado nessas emergências: por aí vamos construindo o futuro".

1 O termo patriarcalismo tem sido utilizado por diversas pesquisadoras feministas, que fazem uma aproximação entre o patriarcado e o desenvolvimento do capitalismo. Cito como exemplo as obras das brasileiras Heleieth Saffioti $(1987,2004,2013)$ e Neuma Aguiar (1997). Este conceito não é desenvolvido neste texto, pois extrapola as intenções do mesmo. 


\section{REFERÊNCIAS}

AGUIAR, N. Perspectivas feministas e o conceito de patriarcado na sociologia clássica e no pensamento sociopolítico brasileiro. In: AGUIAR, N. (Org.). Gênero e ciências humanas: desafio às ciências desde a perspectiva das mulheres. Rio de Janeiro: Rosa dos Tempos, 1997. p. 161-191.

BLAY, E. A. Núcleos de estudos da mulher X academia. In: ENCONTRO NACIONAL DE NÚCLEOS E GRUPOS DE PESQUISAS, 1., 2005/2006. Anais: Pensando gênero e ciência. Brasília: Secretaria de Políticas para as Mulheres/SPM, 2006.

BRUSQUINI, C.; BARROSO, C. Caminhando juntas: uma experiência em educação sexual na periferia de São Paulo. Cadernos de Pesquisa, São Paulo, n. 45, 1983.

CHASSOT, Á. I. A ciência é masculina? É sim, senhora! 2. ed. São Leopoldo: Unisinos, 2006.

COLLING, A. M. Tempos diferentes, discursos iguais: a construção do corpo feminino na história. Dourados: UFGD, 2014.

ESMERALDO, G. G. S. L. Marcas de novas institucionalidades nas universidades criadas por núcleos e redes acadêmicas e feministas. In: Pensando gênero e ciência. ENCONTRO NACIONAL DE NÚCLEOS E GRUPOS DE PESQUISAS, 2., 2009. Anais... Brasília: SPM, Presidência da República, 2010, p. 91-101. Disponível em: <http://www.spm.gov. br/arquivos-diversos/publicacoes/publicacoes/spm-nucleos-web.pdf/view $>$. Acesso em: 20 fev. 2012.

FEDERICI, S. Calibã e a bruxa: mulheres, corpo e acumulação primitiva. São Paulo: Elefante, 2017.

FOUCAULT, M. História da sexualidade I: a vontade de saber. Rio de Janeiro: Graal, 1984.

FRIGOTTO, G. Escola sem partido: imposição da mordaça aos educadores. $1^{\circ}$ jul. 2016. Cpers Sindicato. Não paginado. Disponível em: $<$ http://cpers.com.br/escola-sem-partido-imposicao-da-mordaca-aos-educadores/>. Acesso em: 10 ago. 2016.

HELLER, A. O cotidiano e a história. São Paulo: Paz e Terra, 2008.

SAFFIOTI, H. O poder do macho. São Paulo: Moderna, 1987.

SAFFIOTI, H. Gênero, patriarcado, violência. São Paulo: Perseu Abramo, 2004.

SAFFIOTI, H. A mulher na sociedade de classes: mito e realidade. São Paulo: Expressão Popular, 2013.

SANTOS, B. de S. A crítica da razão indolente: contra o desperdício da experiência. São Paulo: Cortez, 2000. 
SANTOS, B. de S. Renovar a teoria crítica e reinventar a emancipação social. São Paulo: Boitempo, 2007.

SCHIEBINGER, L. O feminismo mudou a ciência? Bauru: EDUSC, 2001.

SCOTT, J. Gênero: uma categoria útil de análise histórica. Educação e Realidade, Porto Alegre, v. 20, n. 2, jul./dez. 1995.

UNIVERSIDADE FEDERAL DE PELOTAS (UFPEL). Observatório de Gênero e Diversidade. Disponível em: <http://wp.ufpel.edu.br/observatorio> Acesso em: 14 ago. 2016.

WEREBE, M. J. G. Sexualidade, política e educação. Campinas: Autores Associados, 1998.

Texto recebido em 09 de março de 2018.

Texto aprovado em 03 de junho de 2018. 
